\title{
Path Research for Energy Conservation and Emission Reduction in Power Industry Based on the Low Carbon Economy
}

\author{
Anrong $\mathrm{Hu}^{1, \mathrm{a}}$ \\ ${ }^{1}$ Economics and Management School, Wuhan University, Wuhan, China \\ aanronghu@163.com
}

\begin{abstract}
Keywords: Low Carbon Economy, Energy Conservation and Emission Reduction, Power Generation Industry;
\end{abstract}

\begin{abstract}
In global climate warming, energy shortage, pollution increasingly serious international background, the development of marked by low energy consumption, low emissions of low-carbon economy and sustainable development are becoming the common choice of economic development around the world. Low carbon economy is a new choice of China faces, new opportunities. New challenges are to improve the ecological environment and promote the development of the change of the pattern of economic development pattern. Power industry is as the most energy consumption. $\mathrm{CO}_{2}$ emissions as one of the largest sector of the future development path is correct or not directly affects the effect and the success or failure of the low carbon economy in our country. Power industry energy conservation and emissions reduction under low carbon economy theory research of the path is feasible and provides reference to the planning power industry in our country and draw lessons from. It has good theoretical value and practical significance.
\end{abstract}

\section{Introduction}

Climate warming has become a 21st century one of the most serious challenges facing humanity. Global warming will cause the melting glaciers, rising sea levels and frequent natural disasters. The deep influence of agriculture and food security is ecological security. Public health security and energy security, such as a direct threat is to human survival and development. Connotations framework of low carbon city is seen as Fig. 1. And increasing greenhouse gas emissions from human activity is one of the most main cause of global warming. It has found atmosphere can produce nearly 30 kinds of greenhouse gases, which play an important role in our fleet. In the greenhouse gases causing global warming effect, the effect of our fleet is as high as $77 \%$. Therefore, to reduce the emissions of our fleet is an important problem to be solved.

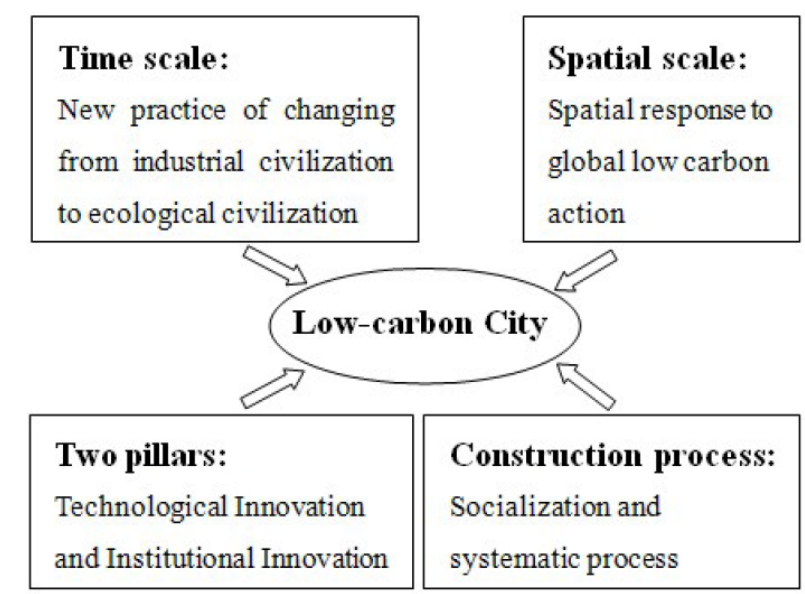

Fig. 1. Connotations framework of low carbon city

Low carbon economy is not a simple technical or economic issue. It involves politics, society, environment, international and many other issues. Any country and any areas develop low carbon economy alone cannot achieve the reduction of global greenhouse gas emissions. All countries 
around the world need all groups to discuss. In power generation industry in China is as our fleet emissions in the national economy one of the largest, accounting for $38.76 \%$ of carbon emissions. Our country electric power production is given priority to with coal energy use by a coal accounts for the proportion of the power structure of more than $70 \%$. Because it has a longer service life of a generator, the power industry has a strong carbon lock effect. The electric power industry for a long time of our fleet emissions will be locked by the current power structure. Therefore research under the background of low carbon economy under the premise of how to ensure continuous and stable development to achieve energy conservation and emissions reduction. It is an important problem faced by the current power industry.

$$
d_{i}=\left\{\sum_{j=1}^{m}\left(\mathrm{w}_{i j} \mathrm{r}_{i j}-\mathrm{w}_{i j} \mathrm{~B}_{j}\right)^{2}\right\}^{1 / 2}
$$

In view of the power industry in our country's low carbon economic development, energy conservation and emissions reduction work has the pivotal status in the country very concerned about the problems of study. The state council development research center dedicated to entrust our group submitted a report to study this problem. The purpose is for the national electric power industry under low carbon economy development planning Suggestions to provide reference for the relevant policies of the state council. In this report, this article is based on a more thorough and systematic research and analysis. It puts forward based on low carbon economy of electricity industry development path of energy conservation and emissions reduction.

\section{Low Carbon Economy Related Theory}

From the connotation of low carbon economy for the low carbon and economic two aspects, the low-carbon economy is to tackle climate change. Human society is to achieve sustainable economic and social development of a model. Structure of the system based on Mas is seen as Fig. 2. Low carbon means that economic development must minimize or stop the reliance on carbon-based fuels to achieve energy transformation and economic transition. Economy means in the process of energy transformation continue to maintain the stability and sustainability of economic growth. Supporting Element of Low carbon Economy is seen as Fig. 2. This idea cannot be exclusive development and maximum output and also do not reject long-term economic growth.

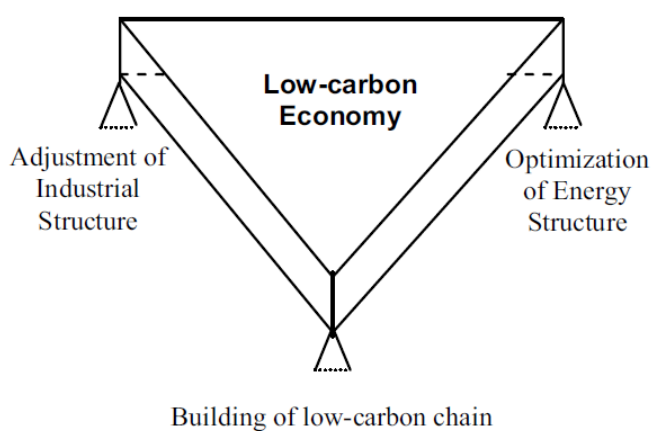

Fig. 2. Supporting Element of Low carbon Economy

Under the background of low carbon economy power industry energy conservation and emissions reduction goal is to ensure that the coordinated development of economic and environmental benefits. Power generation industry economic benefit determines the driving force for the development of the electric power production and national economic development level, so the power industry should not be any cost, energy saving and emission reduction to achieve the balance of economic and environmental benefits, the overall optimal. Only in this way can fully motivate power generation industry lasting inner motive power of energy conservation and emissions reduction, to ensure that keeps the stabilization of electric power production and eventually achieve the goal of sustainable development. 


\section{The Basic Connotation of Power Industry Energy Conservation and Emissions Reduction Path}

Based on low carbon economy in power generation industry compared with the traditional power industry energy conservation and emissions reduction, energy saving and emission reduction on the connotation of stressed the two content of carbon emission reduction and new energy power generation. The origin of low carbon city is seen as Fig. 3. Power industry energy conservation and emissions reduction work begins in China during the period of 11th five-year plan.

$$
\begin{aligned}
& F(\mathrm{X})=\operatorname{opt}\left\{\mathrm{f}_{1}(\mathrm{x}), \mathrm{f}_{2}(\mathrm{x})\right\} \\
& =\left\{\begin{aligned}
\min \mathrm{f}_{1}(\mathrm{x})= & \sum_{j=1}^{m} x_{j, t} \times b_{j, t} \times K_{j, t}^{C O_{2}} \\
\min f_{2}(\mathrm{x})= & \left\{\sum_{j=1}^{m}\left(\frac{x_{j, t}-x_{j, t-1}}{H_{j, t}} \times M_{j, t}+\frac{x_{j, t}}{H_{j, t}} \times M_{j, t} \times a_{j, t}\right)+\right. \\
& \sum_{j=1}^{m}\left[\left(\mathrm{x}_{j, t} \times \mathrm{b}_{j, t} \times \mathrm{p}_{j, t}\right)+\right. \\
& \left.\left.\sum_{k=1}^{n_{k}}\left(\mathrm{x}_{j, t} \times \mathrm{b}_{j, t} \times \mathrm{s}_{j, k, t} \times \mathrm{v}_{j, k, t}\right)+A_{j, t}\right]\right\} \times(1+\mathrm{i})^{-t}
\end{aligned}\right.
\end{aligned}
$$

Energy saving in the power industry energy conservation and emissions reduction is nonrenewable fossil energy consumption saving, reducing energy consumption per unit power. Reduction is to point to reduce sulfur dioxide, nitrogen oxides, dust, solid waste, emissions of pollutants such as wastewater. Power industry energy conservation and emissions reduction based on low carbon economy connotation on the basis of the original reinforced carbon dioxide emissions, to emphasize the new energy power generation, water power, wind power, solar power, nuclear power, biomass power generation, also highlights the low-carbon technology innovation, etc.

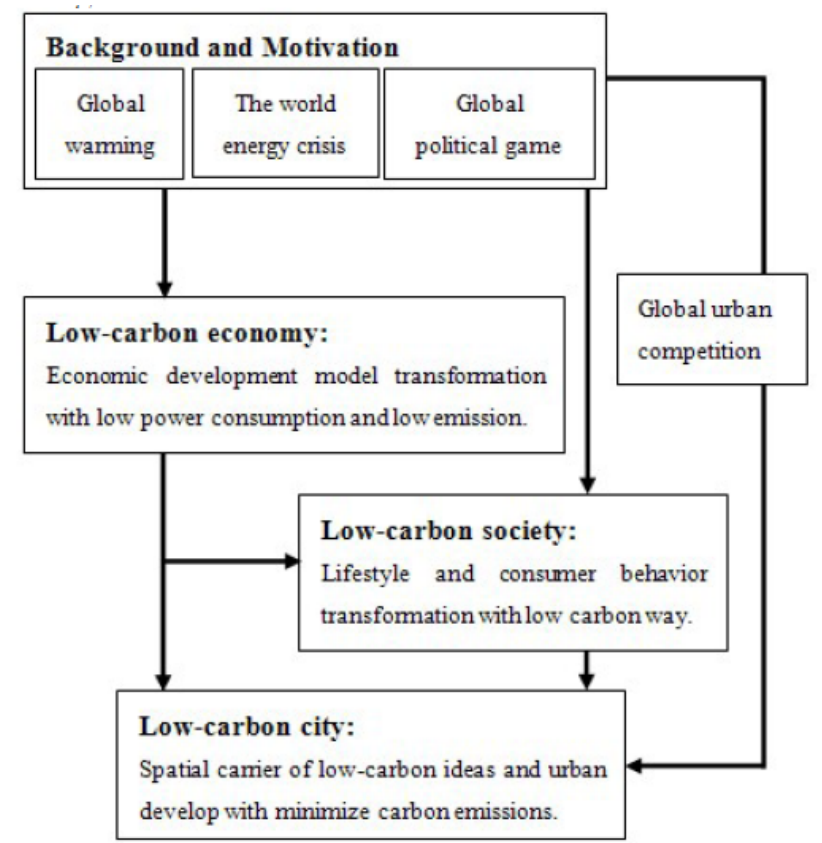

Fig. 3 . The origin of low carbon city

The safety of electric power mainly includes two aspects: the first on the one hand is a one-off energy supply security. On the other hand, different kinds of power supply reliability of power production. The renewable energy resources in our country is very rich, but because of the instability of hydropower, wind power, hydropower, wind power supply safety will be reduced. And different kinds of power supply reliability and power, the power supply security of the thermal power is the highest. The reserves of uranium is higher. Promotion model of low-carbon economy based on low-carbon chain is seen as Fig. 4. Nuclear power supply security also is stronger. Hydroelectric 
power because of the water resources, water and the plentiful, lead to hydroelectric power reliability is affected. To sum up, the safety of power supply from high to low can be divided into thermal power, nuclear power, hydropower and wind power.

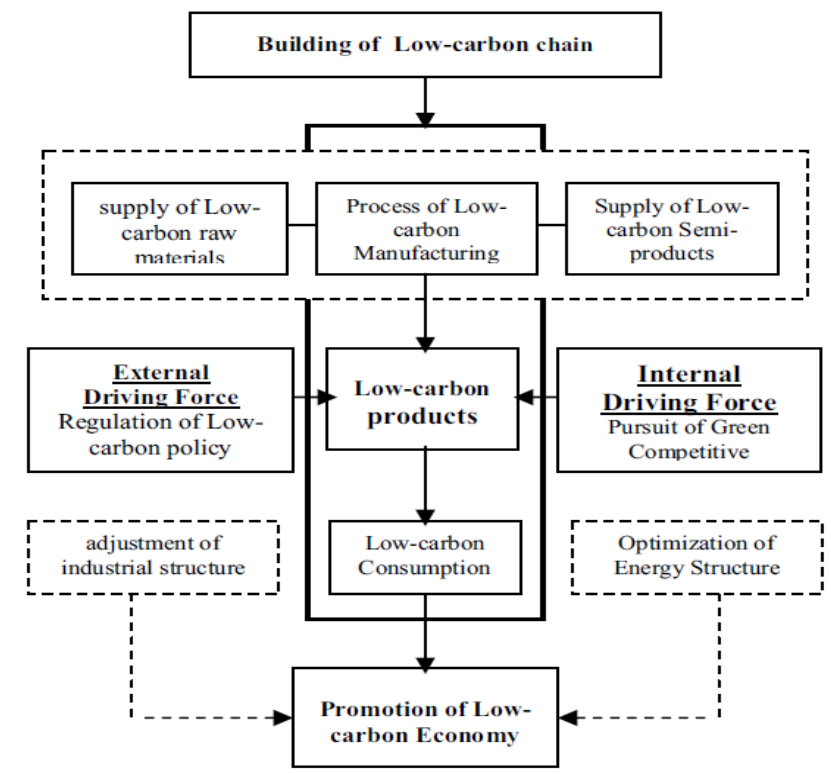

Fig. 4. Promotion model of low-carbon economy based on low-carbon chain

\section{Conclusions}

Paper according to the power industry energy conservation and emissions reduction under low carbon economy path analysis, put forward a series of guarantee power generation industry based on low-carbon economy path. It realizes the energy saving and emission reduction policy Suggestions, including sound power industry energy conservation and emissions reduction under low carbon economy under the laws and regulations to improve the low carbon economy of electricity industry economic policy of energy conservation and emissions reduction, improvement of power industry energy conservation and emissions reduction under low carbon economy under the market mechanism. It strengthens low carbon economy of electricity industry supervision and so on four aspects of energy conservation and emissions reduction.

\section{References}

[1] L. Lu and X.R. Guo, The research progress of low carbon reduction countermeasures of the power industry, Environmental Science and Technology, 33(12), 2010, 355-360.

[2] Q.W. Li and D.W. Zhang, Break carbon depend on to a low-carbon economy, China Electric Power Enterprise Management, 74(11), 2009, 19-20.

[3] S.J. Lu, S.X Yang and Y.T. Lin, Under the low carbon economy development and research of the power industry, Journal of China National School of Administration, 28(2), 2010, 46-50.

[4] Y.J. Wang, S. Xue and X.L. Zhu, Based on MILP - ANN method of low-carbon intelligent island distributed generation management model, East China Electric Power, 39(9), 2011, 1414-1418. 